\title{
Fungal communities in the biofilms colonizing the basalt sculptures of the Leizhou Stone Dogs and assessment of a conservation measure
}

\author{
Yali Wang ${ }^{1}$, Huan Zhang ${ }^{1 *}$, Xiaobo Liu ${ }^{2}$, Xiaoqing Liu ${ }^{1}$ and Wei Song ${ }^{1}$
}

\begin{abstract}
The Leizhou Peninsula in China is very famous for its unique folk art creation, especially for the stonework, like the basalt sculptures of the Leizhou Stone Dogs, which have a history of more than two thousand years. Since these sculptures are usually exposed outdoors, many of them are suffering from severe damage by lichen and fungi. To protect them from microbial attack, we determined fungal communities in the biofilms colonizing the stone dogs and explored an effective conservation measure. Specifically, the micromorphology analysis of the biofilms on the stone dogs was performed through both on-site and laboratory-based microscopies in order to provide an overview of the fungal community structure. High-throughput sequencing analysis revealed that the predominant fungi in the biofilms belong to the following genera Caloplaca, Chaetomium, Clitopilus, Acanthostigma, Tolypocladium, Aspergillus, and Toxicocladosporium. The energy dispersive X-ray spectrometry (EDS) showed that the basalt is mainly composed of silica (53\% by weight), followed by $\mathrm{Al}_{2} \mathrm{O}_{3}(14.4 \%), \mathrm{Fe}_{2} \mathrm{O}_{3}(10.1 \%), \mathrm{CaO}(8.4 \%)$, and $\mathrm{MgO}(7.4 \%)$ that are oxides susceptible to corrosion of biogenic acids. The EDS analysis of the hyphae provided the direct evidence on the leaching of the minerals of the sculptures. To control microbial attack, three kinds of antimicrobial agents were tested for 2 years. As a result, the mixture of biocide and water repellent showed the best effectiveness. Our findings provide an overview of fungi diversity in the biofilms on the stone dogs and help the investigation of fungi-induced biodeterioration and the exploration of specific conservation measure.
\end{abstract}

Keywords: Biodeterioration, Biofilms, Fungi, Biocide, Stone dog sculptures, Conservation

\section{Introduction}

Leizhou Stone Dog sculptures in Guangdong, China are typical cultural creative products that blend the ancestors' tradition of totem worship with diverse ethnic cultures $[1,2]$. In ancient times, the Leizhou Peninsula was a wild land and having children was very difficult here because of the local harsh environment [3]. Therefore, the indigenous inhabitants started to worship dogs due

\footnotetext{
*Correspondence: zhhcon@163.com

${ }^{1}$ Guangdong Conservation Centre, Guangdong Museum, 2 Zhujiang East

Road, Guangzhou 510623, Guangdong, China

Full list of author information is available at the end of the article
}

to their robust reproductive capacity. From then on, the stone sculptures of dogs have been widely popular in the Leizhou Peninsula and, thus, have been well known as the Leizhou Stone Dogs, representing the unique cultural heritage that could be dated back to around 200 $\mathrm{BC}$, the Han Dynasty $[4,5]$. Nowadays, a total of about 10,000 stone dogs of diverse meanings and shapes are estimated to be distributed over the Leizhou Peninsula corners, such as the village entrances, the sides of roads or farmlands, and the gate of houses. The majority of them are made of the basalt originated from a local quarry $\left(\mathrm{E} 109^{\circ} 31^{\prime}-110^{\circ} 55^{\prime}\right.$ and $\left.\mathrm{N} 20^{\circ}-21^{\circ} 35^{\prime}\right)$. However, like other stone monuments exposed to the outdoor
Springer Open

(c) The Author(s) 2021. This article is licensed under a Creative Commons Attribution 4.0 International License, which permits use, sharing, adaptation, distribution and reproduction in any medium or format, as long as you give appropriate credit to the original author(s) and the source, provide a link to the Creative Commons licence, and indicate if changes were made. The images or other third party material in this article are included in the article's Creative Commons licence, unless indicated otherwise in a credit line to the material. If material is not included in the article's Creative Commons licence and your intended use is not permitted by statutory regulation or exceeds the permitted use, you will need to obtain permission directly from the copyright holder. To view a copy of this licence, visit http://creativecommons.org/licenses/by/4.0/. The Creative Commons Public Domain Dedication waiver (http://creativecommons.org/publicdomain/zero/1.0/) applies to the data made available in this article, unless otherwise stated in a credit line to the data. 
environment, such stone dogs have also been suffering from both natural weathering of rains or winds and biodeterioration of diverse organisms colonizing on the stone surfaces (Fig. 1), resulting in a considerable loss of the appearance [6].

Importantly, a typical tropical monsoon climate prevails in the Leizhou Peninsula, where microbial activities on stone objects are highly active due to the preferable temperature and humidity over the year. In such environments, diverse microorganisms (e.g., bacteria, archaea, fungi, lichens, and cyanobacteria) often colonize and grow into multispecies biofilms that can lead to the longterm biodeterioration of the stone dogs through their vital activities, such as cell proliferation [7], excretion of corrosive acids [8, 9], biofilm matrix formation [10-12], redox reactions $[13,14]$, and biogeochemical cycles of elements [15-17]. Interestingly, fungi and lichens are widely found in the biofilms on the stone dogs and, thus their activities might be one of the important factors that have led to the biodegradation there.

Such biodeteriogens have been known to promote the biodeterioration of rocks through the physical disruptive pressure of the growing hyphae, further penetration, and bioleaching of mineral constituents $[15,18,19]$. For example, organic acids produced by the filamentous fungi (e.g., Aspergillus niger and
Penicillium frequentans) cause extensive deterioration and destruction of stone materials, including cement/ concrete, limestone, granite and sandstone by dissolving the minerals $[8,20]$. In addition to acidolysis, these organic acids are capable of complexation or adsorption of metal cations (e.g., $\mathrm{Fe}^{2+}$ and $\mathrm{Mg}^{2+}$ ) to the deterioration of the minerals $[8,11,20-23]$. The formation of calcium oxalate on stone matrices is a consequence of the precipitation of calcium carbonate by oxalic acid released by lichens or fungi [20,24, 25]. Although many biodeterioration mechanisms have been reported for fungal biodeteriogens, their diversity and community characterises in the natural multispecies biofilms on stone materials are still under study. Understanding of the fungal communities on the stone dogs is of great importance for the diagnosis of specific biodeterioration processes that are proceeding on the surface and finally helps the development of the corresponding mitigation strategies.

Our study aims to characterize the fungal diversity and community structure in the biofilms colonizing the stone dogs during their two-year exposure to outdoor conditions, examine the biodeterioration activities, and assess the feasibility of an on-site conservation measure. Overall, our findings indicate that a great diversity of fungal communities are present in these biofilms and

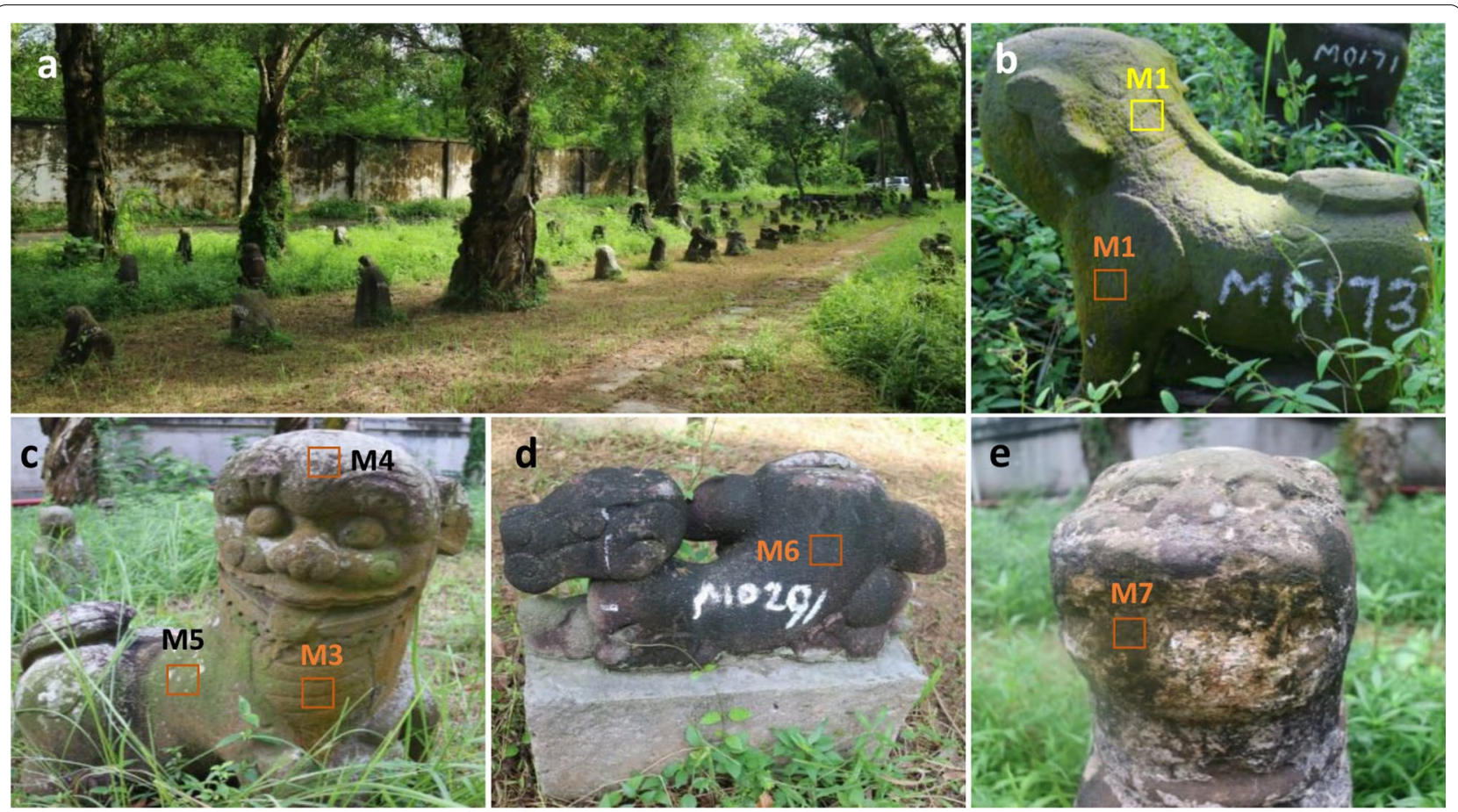

Fig. 1 Stone dogs exposed to the outdoor environment in the Leizhou Peninsula. a An overview of the subject stone dogs displayed in a yard. b-e Are the four stone dogs where biofilms are sampled for the analysis of fungal communities. The labelled sites from M1 to M7 indicate the seven sampling areas (c.a. $5 \mathrm{~cm} \times 5 \mathrm{~cm}$ for each) 
some of the essential considerations should be taken while a conservation practice is performed.

\section{Materials and methods Sampling strategy}

Seven biofilm samples (M1 to M7) were taken from the surfaces of four stone dogs exposed to an outdoor environment in the same yard in the Leizhou Peninsula in the September of 2019 (Fig. 1). Each sampling area was c.a. $5 \mathrm{~cm} \times 5 \mathrm{~cm}$ and biofilms were sampled with a sterile scalpel. Then, samples were separately collected into a sterile petri dish layered with a piece of wet sterile filter paper to keep the humidity. All the dishes were packed into a bag cooled with ice bags and immediately sent to the lab for further analysis.

\section{Analyses of microscopy and energy dispersive X-ray spectrometry}

The on-site analysis of microscopy for biofilms on the stone dogs was performed using the Cordless Digital Microscope DG-3x (Scalar Corporation, Japan). Some biofilm samples were also collected and sent to the lab for further microscopy analysis. For a brief optical microscopy, a drop of the suspension of each sample was transferred onto a microscope slide and examined by the Microscope Axio Imager.A2m (ZEISS) under different magnifications. Stone of the type used to make the sculptures of the stone dogs was collected from the local quarry for the analysis of chemical composition of the materials.

The morphology of biofilms and chemical composition of stone samples were assessed by Scanning Electron Microscopy (SEM) and Energy Dispersive Spectroscopy (EDS) assays, respectively. For each type of stone slabs, a small fraction (c.a. $2 \mathrm{~cm} \times 2 \mathrm{~cm}$ ) was separated and fixed with paraformaldehyde (4\% in PBS, Biotium, USA) for the analysis of SEM (FEI Quanta 650 FEG scanning electron microscope, platform of Guangdong Conservation Centre, Guangdong Museum) at an operational acceleration voltage of $5 \mathrm{kV}$ and under low vacuum $\left(3.76 \mathrm{e}^{-1}\right.$ Torr). Images were generated using the backscattered electron detector (BSED). For chemical composition of the stone minerals, a semi-quantitative elemental analysis was conducted by an EDS device (EDAX).

\section{Illumina MiSeq-based high-throughput sequencing}

Total DNA of each biofilm sample was extracted, and internal transcribed spacer (ITS) genes were subject to the high throughput sequencing for analysis of fugal diversity in biofilms colonizing the stone dogs.

\section{DNA extraction}

Biofilm samples were evenly suspended into the sterile distilled water. After that, the suspension was centrifuged at $10,000 \times g$ for $15 \mathrm{~min}$; then, the pellets were re-suspended in the lysis buffer of the ZymoBIOMICS DNA Miniprep Kit D4300 (Zymo Research) and transferred into the ZR BashingBead ${ }^{\mathrm{TM}}$ Lysis Tubes. DNA was extracted following the manufacturer's instructions using the FastPrep-24 5G homogenizer. Finally, the concentration and purity of the extracted DNA were measured using the NanoDrop One Microvolume UVVis Spectrophotometer (Thermo Fisher Scientific, MA, USA).

\section{Amplicon generation}

ITS genes of distinct regions (ITS2) were amplified with a pair of special primers (GCATCGATGAAGAACGCA GC and TCCTCCGCTTATTGATATGC) with $12 \mathrm{bp}$ barcode. Primers were synthesized by Invitrogen (Invitrogen, Carlsbad, CA, USA). The PCR reaction system (a total volume of $50 \mu \mathrm{l}$ ) contained $25 \mu \mathrm{l}$ of the $2 \times$ Premix Taq (Takara Biotechnology, Dalian Co. Ltd., China), $1 \mu \mathrm{l}$ of each primer $(10 \mathrm{mM}), 3 \mu \mathrm{l}$ of the DNA $(20 \mathrm{ng} / \mu \mathrm{l})$ template, and $20 \mu \mathrm{l}$ of distilled water. Amplicons were amplified by a thermocycling reaction: $5 \mathrm{~min}$ at $94{ }^{\circ} \mathrm{C}$ for initialization, 30 cycles of $30 \mathrm{~s}$ denaturation at $94{ }^{\circ} \mathrm{C}$, annealing at $52{ }^{\circ} \mathrm{C}$ for $30 \mathrm{~s}$, extension at $72{ }^{\circ} \mathrm{C}$ for $30 \mathrm{~s}$, and followed by final elongation at $72{ }^{\circ} \mathrm{C}$ for $10 \mathrm{~min}$. The PCR instrument used was the BioRad S1000 (Bio-Rad Laboratory, CA, USA).

\section{Detection, pooling and purification of the $P C R$ products}

The length and concentration of the PCR product were detected by $1 \%$ agarose gel electrophoresis. Samples with a bright strip at $250 \mathrm{bp}$ were used for further experiments. PCR products were mixed in equal density ratios according to the GeneTools Analysis Software (Version4.03.05.0, SynGene). Then, the mixture was purified with E.Z.N.A. Gel Extraction Kit (Omega, USA). Each project selected the appropriate primers for amplification. When the final primer was not known, it could be viewed in the mapping file of the result package.

\section{Library preparation and sequencing}

Sequencing libraries were generated using NEBNext ${ }^{\circledR}$ Ultra $^{\mathrm{TM}}$ II DNA Library Prep Kit for Illumina ${ }^{\circledR}$ (New England Biolabs, MA, USA) following the manufacturer's guidance, and the index codes were added. The library quality was assessed on the Qubit@ 2.0 Fluorometer (Thermo Fisher Scientific, MA, USA). At last, the library was sequenced on an Illumina Nova6000 platform and 
$250 \mathrm{bp}$ paired-end reads were generated (Guangdong Magigene Biotechnology Co. Ltd., China).

\section{Data processing and taxonomy-based analysis}

FASTP (version 0.14.1, https://github.com/OpenGene/ fastp) was used to control the quality of the Raw Data by sliding window (-W $4-\mathrm{M} 20$ ). The primer sequences were removed using the Cutadapt software (https:// github.com/marcelm/cutadapt/) according to the primer information at the beginning and end of the sequence to obtain the paired-end Clean Reads. Paired-end clean reads were merged using the USEARCH-FASTQ_mergepairs (V10, http://www.drive5.com/usearch/) according to the relationship of the overlap between the paired-end reads, when at least $16 \mathrm{bp}$ overlapped the read generated from the opposite end of the same DNA fragment. The maximum mismatch allowed in the overlap region was $5 \mathrm{bp}$, and the spliced sequences were called the Raw Tags. All the sequences were stored at NCBI under the BioProject of PRJNA691383.

For taxonomy analysis, the Unite database (for ITS, http://unite.ut.ee/index.php) was used to annotate the representative sequence of Operational Taxonomic Unit (OTU) generated with the USEARCH-sintax (set the confidence threshold to default to $\geq 0.8$ ). The taxonomy annotation was divided into seven levels: kingdom (L1), phylum (L2), class (L3), order (L4), family (L5), genus (L6), and species (L7). A rarefaction analysis and coverage were applied to estimate the representation of the phylotypes and to characterize the fungi diversity of these samples. The rarefaction curves were produced with the USEARCH-apha_div_rare (V1, http://www.drive5.com/ usearch/).

In order to study the difference of the dominant species in different samples (groups), the OTU representative sequences with the relative abundance in the top 20 were conducted using the FastTree software, and the relative abundance of each OTU and the annotation of the representative sequence were combined with the ggtree software package for a visual display. To analyse the difference of community structures between samples and test whether or not the differences were significant, the anosim, MRPP, Adonis and AMOVA of vegan and pegas $\mathrm{R}$ packages were employed. The differences between samples were evaluated with alpha diversity index and were subject to both parameter test and non-parameter test.

\section{Antimicrobial treatments}

Three kinds of antimicrobials were used for the cleaning experiments on the surfaces of the stone dogs. An area of the surface evenly colonized by biofilms was selected and divided into four fractions $5-1,5-2,5-3$, and 5-4 (Fig. 2). Each fraction was treated with different biocides. Specifically, the first three fractions $5-1,5-2$, and $5-3$ were brushed with a mixture of fluorosilane BYS4002 and siloxane BYB1007, biocide KY-104, and biocide Sino307 , respectively. Only one layer of antimicrobials was brushed on the surface. The last one 5-4 was used as the control without any antimicrobial treatment. The antibiotic effects against biofilm growth were assessed after

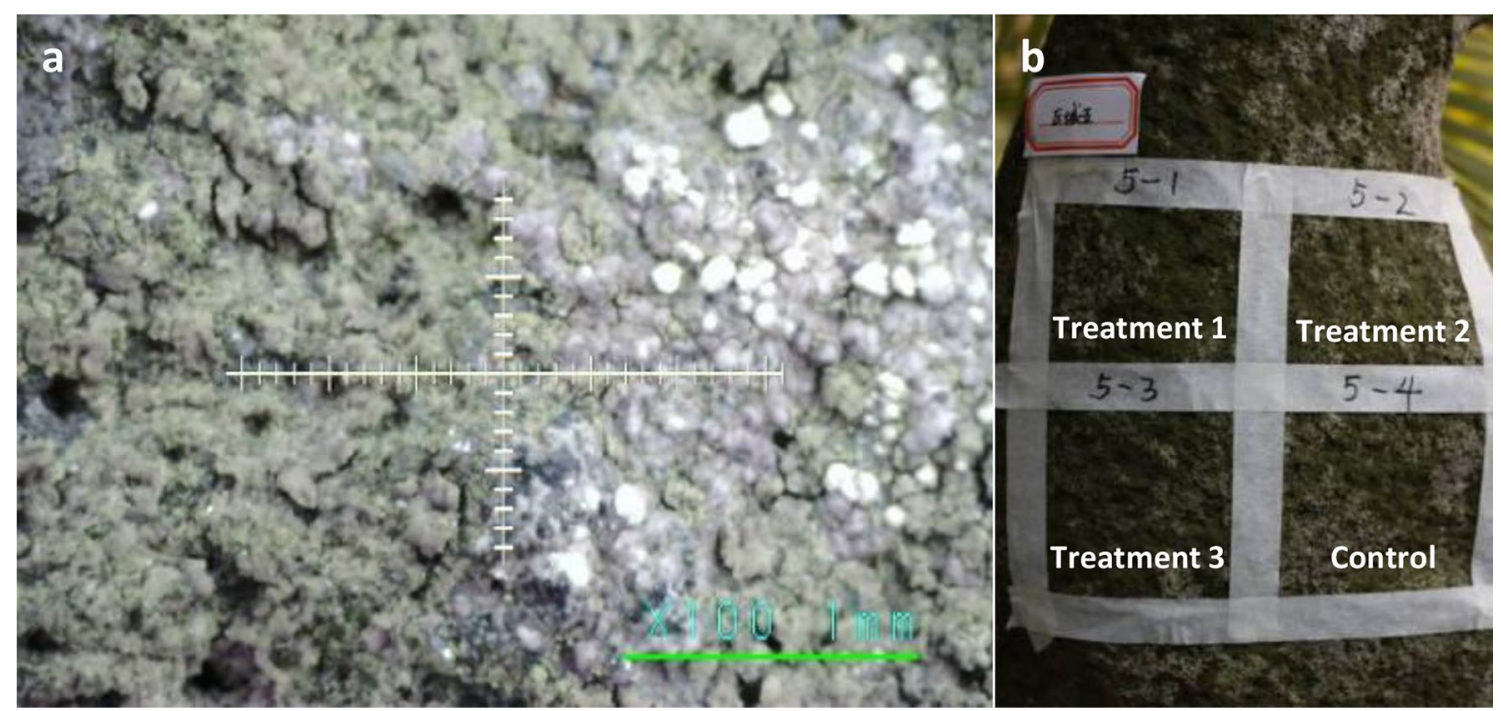

Fig. 2 Assessment of different antimicrobial agents as a conservation measure on a stone dog. a Surface micromorphology of the stone dog used for the conservation experiment. b Setup of the experimental areas treated with a mixture of fluorosilane BYS4002 and siloxane BYB1007 (treatment 1 for the area 5-1), biocide KY-104 (treatment 2 for the area 5-2), and biocide Sino-307 (treatment 3 for the area 5-3). The area 5-4 was used as the control without any antimicrobial treatment 
1 day and after 2 years. Colour differentiations of the surface before and after treatments were analysed with the Cordless Digital Microscope DG-3x.

\section{Results}

\section{Mineral composition of the stone dogs}

The chemical composition analysis showed that the stone material of the Leizhou Stone Dogs is a typical basalt, which is mainly composed of silica (Table 1), accounting for $53 \%$ by weight, followed by $\mathrm{Al}_{2} \mathrm{O}_{3}$ (14.4\%), $\mathrm{Fe}_{2} \mathrm{O}_{3}$ (10.1\%), $\mathrm{CaO}(8.4 \%)$, and $\mathrm{MgO}$ (7.4\%). Like other rocks, silica constitutes of the quartz framework grains of the basalt as it has exceptional hardness and chemical stability, allowing it to survive multiple recycling events. Other components, such as $\mathrm{Al}_{2} \mathrm{O}_{3}$ and $\mathrm{Fe}_{2} \mathrm{O}_{3}$, are usually the cement materials that cement the other minerals around the framework grains. However, most of such mineral constituents are susceptible to the corrosion of both acid rains from air pollutions and biogenic acids from epilithic microbial communities, indicating that the stone dogs are also easy to be deteriorated by both abiotic and biotic processes.

Analyses of microscopy and EDS of the penetrating hyphae The on-site microscopy provided us an overview of colourful biofilms on the stone dogs (Fig. 3). These biofilms indicated that the stone dogs suffer from obvious colonization by diverse microorganisms, mainly including lichens, fungi, algae, and mosses. Based on the further laboratory microscopy, both single-celled algae and filamentous cells or fungi constitute the main biomass of the biofilms (Fig. 4). Moreover, SEM revealed that a mass of hyphae exist in the biofilms and the penetration of hyphae is also visible. Interestingly, EDS of the hyphae that penetrate into the rock showed a high content of the element $\mathrm{Al}$ (Additional file 1: Fig. S1), indicating the biodeterioration of the mineral of $\mathrm{Al}_{2} \mathrm{O}_{3}$ by hyphal cells.

\section{Identification of eukaryotic microorganisms}

The coverage of eukaryotic libraries is all above 96\%, indicating that the major of the biofilm diversities in the clone libraries are detected. In addition, the rarefaction curves generated from our clones reaches the asymptote (Additional file 1: Fig. S2), indicating that the diversity in the libraries is the representative of the community and there is no need for further sampling of more clones.

Taxonomy-based analysis showed that most of eukaryotic microbes in the biofilms belong to fungi (e.g., Ascomycota and Basidiomycota) and algae (e.g., Chlorophyta). This agrees with that lichens as a symbiotic organism of algae or cyanobacteria and filamentous fungi are predominated in some of the biofilms (Fig. 3). The sample M4 has the highest abundance of Ascomycota (83.7\%) and Chlorophyta (5.74\%), compared with the other 6 samples. Specifically, at the genus level, the predominant eukaryotic microbial communities are Chaetomium and Clitopilus in the sample M1, Acanthostigma in the sample M2, Tolypocladium in the sample M3, Caloplaca and Trebouxia in the sample M4, Caloplaca and Acanthostigma in the sample M5, Aspergillus and Toxicocladosporium in the sample M6, and Coniosporium in the sample M7, respectively (Fig. 5). Moreover, the genera Caloplaca, Trebouxia, Aspergillus, Nigrospora, and Phaeophleospora are found to be widely distributed in the biofilms.

At the species level, all of the 20 representative species (excepted one unassigned species) have a similar distribution patterns in the samples M1, M2, M3, and M7 (Fig. 6). Specially, the sample M7 exhibites the highest biodiversity, with the over-representation of seven species, including Devriesia strelitziicola, Phaeophleospora hymenocallidicola, Acanthostigma filiforme, Ochroconis cordanae, Phaeoacremonium fuscum, and Exserohilum rostratum, which however are not the representative species in the sample M6. By contrast, Valsaria neotropica, Myrmecridium schulzeri, Chaetomella raphigera, Robillarda sessilis, and Heterochaete delicate are the overrepresented species in the sample M6. Additionally, Veronica compacta and Trebouxia decolorans are the predominant species in the sample M4. The results showed that the abundance of the specific species might exhibit a large differentiation among the biofilms on the stone dogs, indicating a potential selectivity of the local environmental conditions.

\section{Antimicrobial treatments}

The antibiotic effects of the three kinds of antimicrobials were compared after 1 day and 2 years. After 1 -day treatment, all the three antimicrobials immediately

Table 1 Mineral composition of the Leizhou Stone Dog

\begin{tabular}{|c|c|c|c|c|c|c|c|c|}
\hline Component & $\mathrm{SiO}_{2}$ & $\mathrm{Al}_{2} \mathrm{O}_{3}$ & $\mathrm{Fe}_{2} \mathrm{O}_{3}$ & $\mathrm{CaO}$ & $\mathrm{MgO}$ & $\mathrm{Na}_{2} \mathrm{O}$ & $\mathrm{TiO}_{2}$ & $\mathrm{~K}_{2} \mathrm{O}$ \\
\hline (wt.\%) & 53.3 & 14.4 & 10.1 & 8.1 & 7.43 & 3.17 & 1.38 & 1.21 \\
\hline $\mathrm{P}_{2} \mathrm{O}_{5}$ & $\mathrm{MnO}$ & $\mathrm{SrO}$ & $\mathrm{SO}_{3}$ & $\mathrm{ZnO}$ & $\mathrm{NiO}$ & $\mathrm{Cr}_{2} \mathrm{O}_{3}$ & $\mathrm{CuO}$ & $\mathrm{Cl}$ \\
\hline 0.37 & 0.12 & 0.06 & 0.04 & 0.02 & 0.02 & 0.07 & 0.04 & 0.09 \\
\hline
\end{tabular}



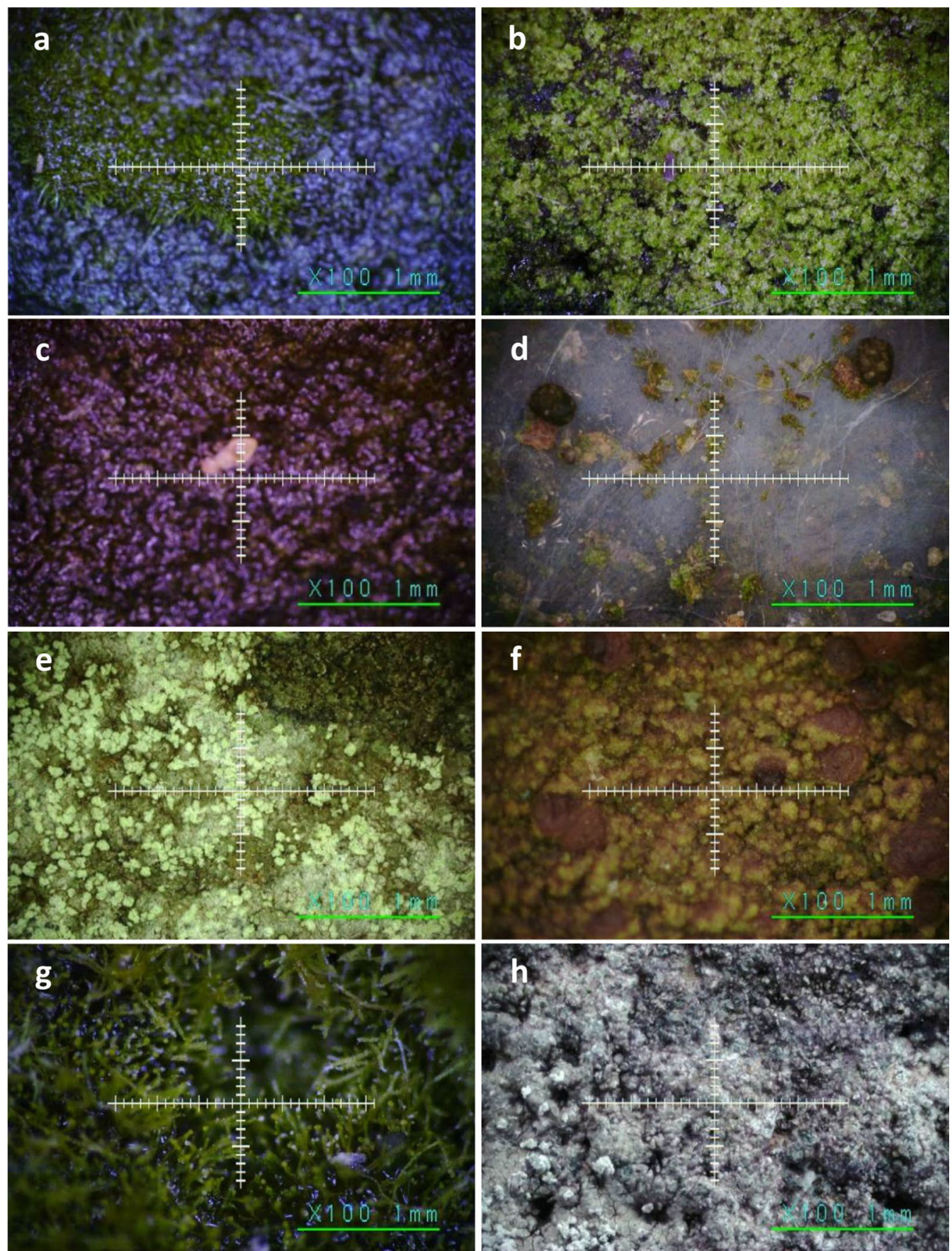

Fig. 3 Micromorphology of colorful biofilms on the surface of the stone dogs using a portable microscope. Lichens (a, b, e, and $\mathbf{g})$, fungi (c, d, $\mathbf{f}$, and $\mathbf{h}$ ), algae, and/or cyanobacteria are predominated in the biofilms

exhibit a good sterilization effect to the biofilms, which are bleached to different extents (Fig. 7). This suggested that all three antimicrobials are effective against the biofilms, and there is no significant difference among them based on the analysis of on-site microscopy and observation by eyes. However, after 2 years, the area 5-2 shows obvious green biofilms, while areas $5-1$ and $5-3$ do not. Hence, it could be inferred that the mixture of fluorosilane BYS4002 and siloxane BYB1007 and the biocide Sino-307 could better inhibit the growth of biofilms than the biocide KY-104. Actually, the mixed biocide is found to be the most effective antimicrobial agent. 

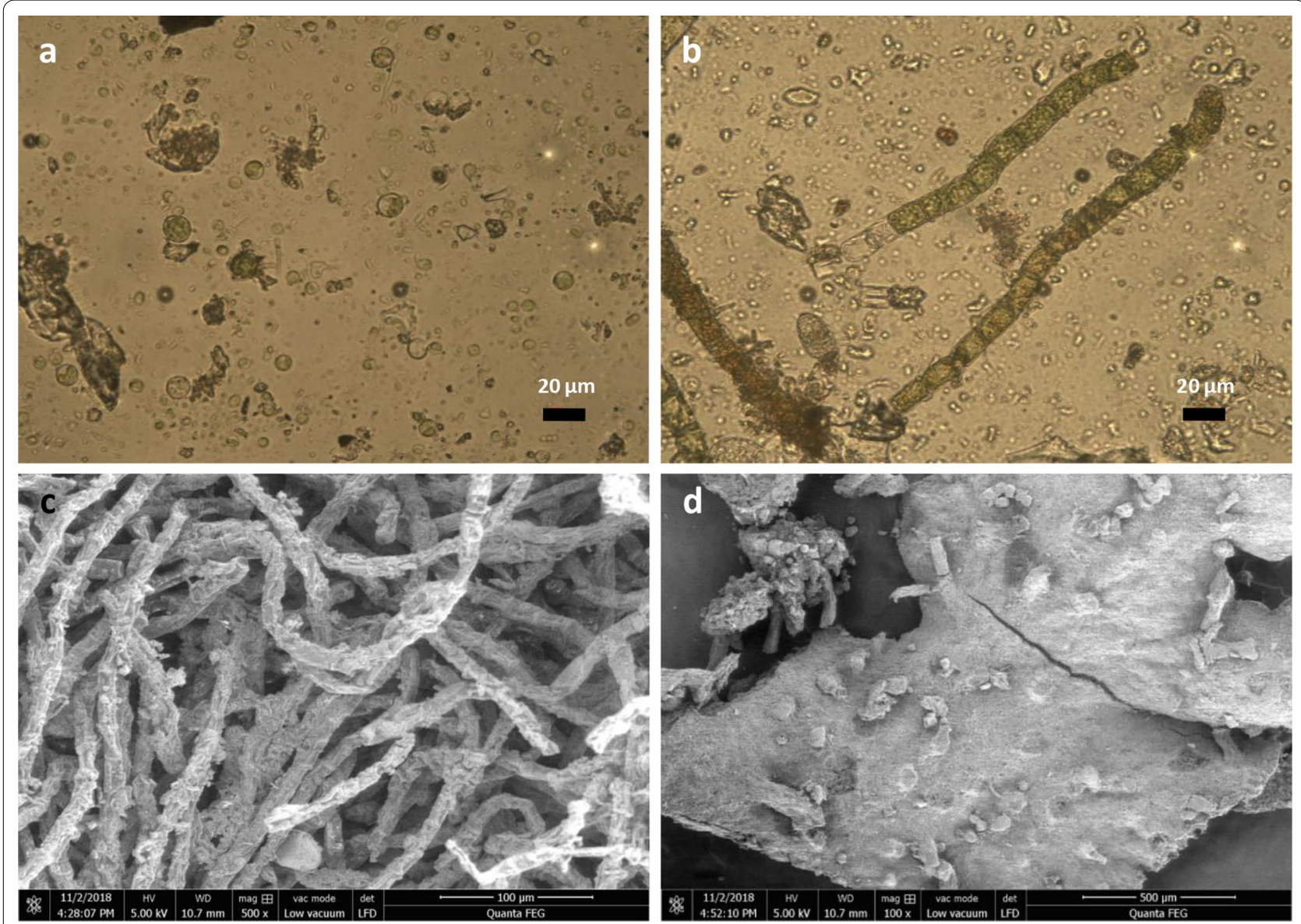

Fig. 4 Laboratory-based microscopy of the selective biofilm samples. Light microscopy of the biofilm samples: a single cells; and $\mathbf{b}$ filamentous cells. Scanning electron microscopy of lichens: $\mathbf{c}$ the hyphae of lichens; and $\mathbf{d}$ the hyphae penetrating into the stone dog

\section{Discussion}

Microbial biofilms on stone monuments and buildings have been mainly reported to be bacteria, fungi, algae, archaea, and lichens (a symbiont of fungi and algae) [11, 26]. In this study, different colour biofilms are observed on the surfaces of the stone dogs, which severely cause the discoloration of the appearance. For example, photosynthetic communities could rely on the photosynthesis to fix $\mathrm{CO}_{2}$ and provide organic compounds for fungi or other heterotrophic microorganisms $[15,18,21]$. On the one hand, the growth of photosynthetic communities could stain the surface green (Fig. 1b) [27, 28]. On the other hand, they support the development of fungi that have great impacts on the stone dogs. For example, some sulfur-oxidizing fungi have been reported to release sulfuric acid involved in the formation of calcium sulfate that results in harmful black crusts on the surface of stone [29], as seen in Fig. 1d. Here, we detected the dominated fungi or algae in the biofilms on the stone dogs, including Caloplaca, Chaetomium, Clitopilus, Acanthostigma, Tolypocladium, Aspergillus, and Toxicocladosporium, which have been reported to be the common biodeteriogens of stone materials [20,30,31]. For one, Chlorophyta are the typical phototrophs observed on stones and also involved in the discoloration of green pigments [32]. The genus Ascomycota is the main communities that often form sooty mycelia and melanin pigments in the porous space of the stones, as seen in the sample M4 (Fig. 1c) [33]. Besides, Ascomycota (e.g., Pyrenula sanguinea) are also lichenised fungi [33]. The species in the genus Caloplaca often exhibit a variety of colours [34] and, thus result in the discoloration of the stone surfaces.

It is well known that fungi and lichen can influence the biodeterioration of stone through both biophysical and biochemical processes. One of the important physical processes is the penetration of hyphae [15], which can cause substantial mechanical damage to the stability of stone, as seen in Fig. 4 . The growth of hyphae may result in the formation of the fissures or pores and make the stone surface lose its hydrophobic properties due to the retention of water [35]. Thus, this will greatly accelerate the biodeterioration process because water is essential 


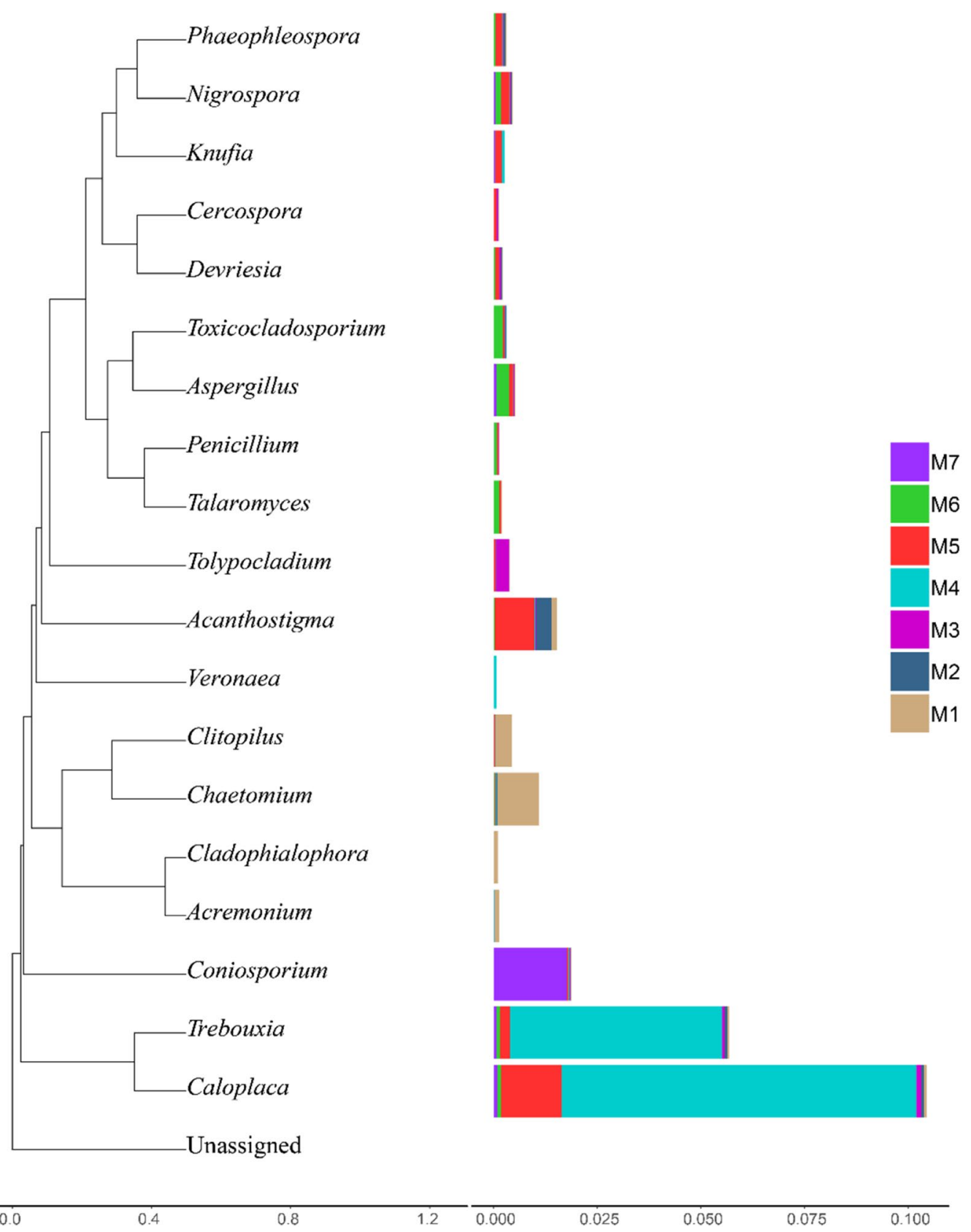

Fig. 5 Genus distribution of eukaryotic microbial communities among the seven samples. The tree was established by clustering analysis of a sample similarity of the microbial composition, and the horizontal bar chart shows the relative abundance of the corresponding genus in each sample

for both chemical reactions between biogenic acids and minerals and the growth of microorganisms on or inside the stone [36].

Filamentous fungi or lichens have also caused extensive deterioration and destruction of stone materials by biogenic acidic corrosion. For example, some sulfuroxidizing fungi (e.g., Fusarium solani) can obtain energy by oxidizing the reduced or elemental sulfur to sulfurous or sulfuric acid that reacts with the minerals of stone monuments and buildings [37, 38]. The cement materials, such as $\mathrm{Al}_{2} \mathrm{O}_{3}$ and $\mathrm{Fe}_{2} \mathrm{O}_{3}$, are prone to the dissolution of these inorganic acids [15], with substantial $\mathrm{Fe}^{3+}$ and $\mathrm{Al}^{3+}$ leaching out. In addition to acidolysis, fungi and lichens are usually the producers of many organic acids, such 


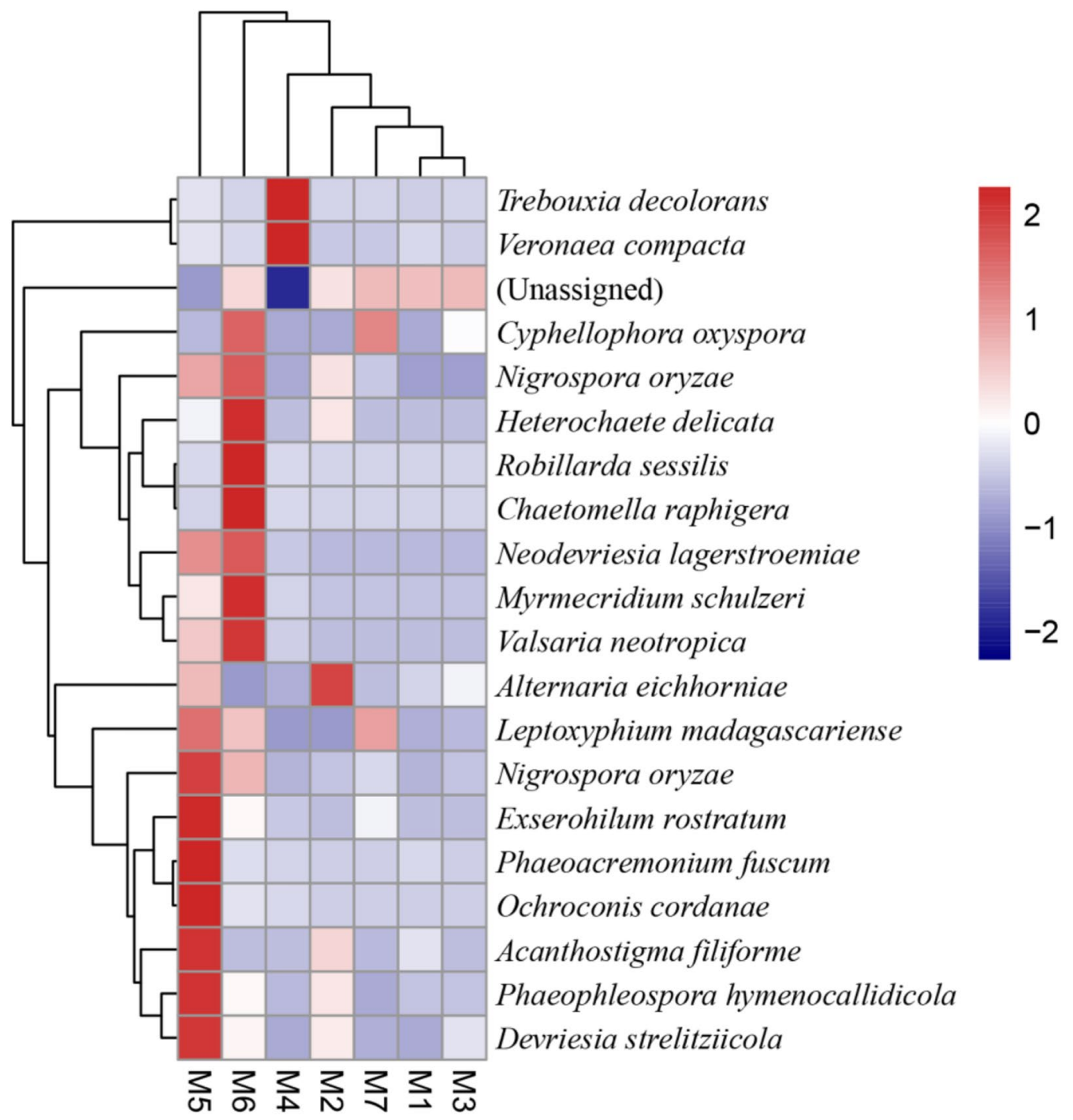

Fig. 6 Heat map analysis by clustering the most 20 abundant OTUs identified by Illumina-based sequencing of both the 18S rRNA gene and ITS fragments datasets. Clustering and heat map analyses were conducted to visualize the assigned species and their representation in each sample. The representation is based on the relative abundance of a species in a given sample and the mean abundance of this species over the seven samples

as volatile fatty, citric, succinic, oxalic, and malic acids, which have diverse influences on the biodeterioration of mineral constituents to distinct extents [20,39]. For one, lichens or fungi can release oxalic acid that is responsible for the formation of calcium oxalate on stone matrices, giving rise to the precipitation of calcium carbonate [20, 24, 25]. Moreover, these organic acids are capable of complexation or adsorption of released metal cations (e.g., $\mathrm{Al}^{3+}, \mathrm{Fe}^{2+}$ and $\mathrm{Mg}^{2+}$ ) $[8,11,20-23]$. Thus, the pioneer lichens can create a favourable microenvironment for the subsequent colonisers in the biofilms by increasing the bioavailability of mineral elements and nutrients.
To confirm this inference, the EDS analysis of the green biofilms is performed. As a result, a high content of $\mathrm{Al}$ is detected in the hyphae. Other studies reported that the growth of lichens results in the formation of ferromagnesian minerals and makes the surface calcium-rich, thus leading to the release and deposition of metal cations (e.g., $\mathrm{Al}^{3+}, \mathrm{Fe}^{2+}$ and $\mathrm{Mg}^{2+}$ ) from the primary minerals [40-42]. However, such chemical reactions are usually the complex and long-term processes and few studies document the biodeterioration mechanisms of specific fungal species. Further experiments on site or in the laboratory are required to confirm the roles of specific 

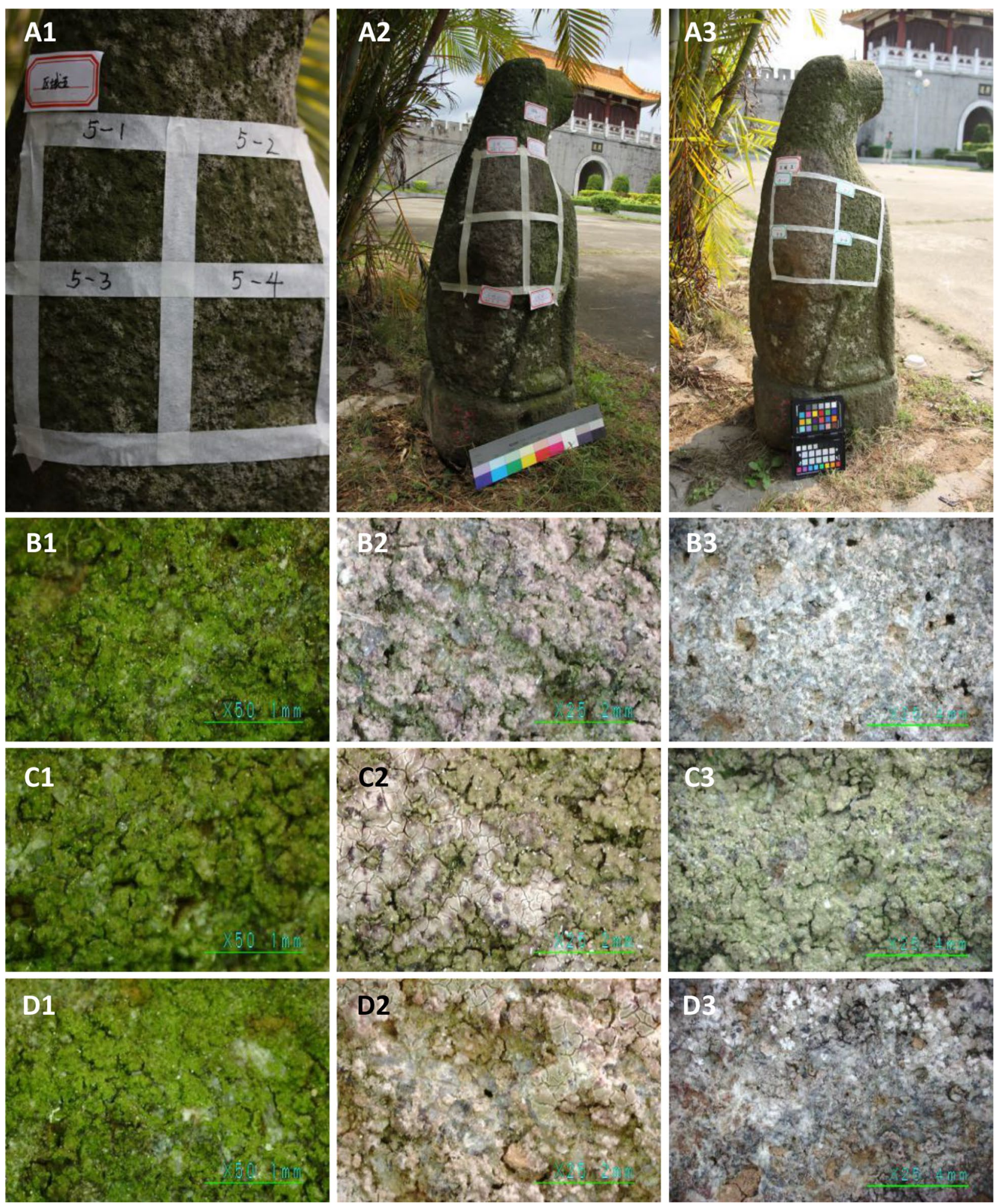

Fig. 7 Comparison of surface micromorphology before and after antimicrobial treatments. Images a1-a3 are an overview of the surface before treatment, 1 day after treatment, and 2 years after treatment, respectively. On-site micrographs b1-b3 show the micromorphology of the area 5-1 before treatment, 1 day after treatment, and 2 years after treatment, respectively. On-site micrographs $\mathbf{c} \mathbf{1}-\mathbf{c} \mathbf{3}$ show the micromorphology of the area $5-2$ before treatment, 1 day after treatment, and 2 years after treatment, respectively. On-site micrographs $\mathbf{d} \mathbf{1}-\mathbf{d} \mathbf{3}$ show the micromorphology of the area 5-3 before treatment, 1 day after treatment, and 2 years after treatment, respectively 
species in the biodeterioration of the basalt sculptures of the stone dogs.

For conservation of the stone dogs, the first step is to remove or kill the microorganisms on the stone. Microbial colonization on stones depends on environmental factors, such as water, light, nutrient sources, and other parameters [15]. Hence, controlling any of the essential factors can prevent microbial growth. As most of the stone dogs are exposed outdoors, controlling of temperature and sunlight cannot be achieved. However, water is a major limiting factor for the development of microbial biofilms [36]. Choosing an appropriate water-repellent material may be effective for biofilm control on the stone dogs. In this study, the mixed antimicrobial seems to work well probably because it is added with an antiweathering material that allows a water-repellent effect. Although the other two biocides are also effective at the early stage, but their effects are not better than the antimicrobial mixed with a water-repellent agent.

Although, no side-effect is observed after 2 years, evaluation of the longer effectiveness of the treatment is still required; for example, effects of antimicrobial treatments on ecological systems and stone properties, including colour, density, and porosity. Considering the sideeffects, some reports recommended not to use biocides or hydrophobic preservation materials. For example, the Lascaux Cave of biocide treatments has suffered from a disaster of microbial communities composed of humanpathogenic bacteria and entomopathogenic fungi, with the former as a result of the biocide selection [43]. Silicone tabia preservation materials with different hydrophobicity are found to damage tabia relics through salt crystallization, moisture and thermal expansion [44]. Thus, on the one hand, a comprehensive evaluation of the long-term effect of treatment with water repellents or biocides is required. On the other hand, developing some environmentally-friendly biocides, such as chitosanbased fungicides [45] and biological control agents [46, 47], will reduce the side-effects on the environment and the stone structure.

\section{Conclusions}

The basalt sculptures of the Leizhou Stone Dogs are undergoing severe biodeterioration of colourful biofilms, in which lichens and fungi are widely distributed. Among them, the predominated communities are found to be Caloplaca, Trebouxia, Chaetomium, Clitopilus, Acanthostigma, Tolypocladium, Aspergillus, and Toxicocladosporium. These biofilm communities could deteriorate the basalt sculptures via the penetration of hyphae or dissolution of metal oxides $\left(\mathrm{Al}_{2} \mathrm{O}_{3}\right.$ and $\left.\mathrm{Fe}_{2} \mathrm{O}_{3}\right)$. Antimicrobial treatments showed that a mixture of siloxane and fluorosilane would be the best agent for a long-term conservation, but a more comprehensive evaluation of the long-term effect of the treatment is required before the application at a large scale.

\section{Supplementary Information}

The online version contains supplementary material available at https://doi. org/10.1186/s40494-021-00508-1.

Additional file 1: Figure S1. Energy dispersive X-ray spectrometry analysis of the penetrating hyphae. Figure S2. Rarefaction curves of the seven samples showing the biodiversity of fungi in the biofilms.

\section{Acknowledgements \\ Not applicable.}

\section{Authors' contributions}

$\mathrm{HZ}$ conceived and designed the research. YW, XL (Xiaoqing Liu), and WS performed the research and analyzed the data. YW and XL (Xiaobo Liu) wrote the manuscript. XL (Xiaobo Liu) helped perform the analysis and edit the manuscript. All authors read and approved the final manuscript.

\section{Funding}

This work was supported by grants from: Cultural Heritage Conservation Fund of Guangdong Provincial Government, China; Cultural Prosperity Development Fund of Guangdong Provincial Government, China.

\section{Availability of data and materials}

The data is available within the article.

\section{Declarations}

Ethics approval and consent to participate

Not applicable.

\section{Consent for publication}

Written informed consent for publication was obtained from all participants.

\section{Competing interests}

The authors declare that they have no competing interests.

\section{Author details}

${ }^{1}$ Guangdong Conservation Centre, Guangdong Museum, 2 Zhujiang East Road, Guangzhou 510623, Guangdong, China. ${ }^{2}$ Environmental Engineering Program, Guangdong Technion-Israel Institute of Technology (GTIIT), 241

Daxue Road, Shantou 515063, Guangdong, China.

Received: 23 October 2020 Accepted: 11 March 2021

Published online: 22 March 2021
References

1. Lu C. Research on the modeling design of cultural creative products of "Leizhou stone dog." Int J New Dev Eng Soc. 2020;4(1):226-35.

2. Xiuli Z. Leizhou's Shigou customs: a cultural research. J Zhanjiang Norm Coll. 2011;4 (in Chinese).

3. Li R-X, Lin D, Liu Z-W, Liu S-Z, Huang L-L. The Leizhou stone dog as cultural heritage. J Wuyi Univ (Soc Sci Ed) 2007;2. (in Chinese).

4. Liufu J, Li XX. The clarification of the ethnic origin of Lingnan stone dog worship. J Guangdong Polytech Norm Univ. 2013;11:5 (in Chinese).

5. YanZhuang H-LX-S. Aesthetic analysis of the supernatural dog in the dog worshiping culture in Leizhou. J Guangxi Univ Natl (Philos Soc Sci Ed). 2013;5:19 (in Chinese)

6. Zhang H, Liu X. A study on the problems and conservation of Leizhou stone dogs, Guangdong, China. Stud Conserv. 2014;59(sup1):S195-8. 
7. Adhikary SP, Keshari N, Urzì C, De Philippis R. Cyanobacteria in biofilms on stone temples of Bhubaneswar, Eastern India. Algol Stud. 2015;147(1):67-93.

8. De Windt L, Devillers P. Modeling the degradation of Portland cement pastes by biogenic organic acids. Cem Concr Res. 2010;40(8):1165-74.

9. Palmer RJ, Siebert J, Hirsch P. Biomass and organic acids in sandstone of a weathering building: production by bacterial and fungal isolates. Microb Ecol. 1991;21(1):253-66.

10. Kemmling A, Kämper M, Flies C, Schieweck O, Hoppert M. Biofilms and extracellular matrices on geomaterials. Environ Geol. 2004;46(3):429-35.

11. Martino PD. What about biofilms on the surface of stone monuments? Open Conf Proc J. 2016;6(Suppl 1: M2):14-28.

12. Gaylarde CC, Rodríguez CH, Navarro-Noya YE, Ortega-Morales BO. Microbial biofilms on the sandstone monuments of the Angkor Wat complex Cambodia. Curr Microbiol. 2012;64(2):85-92.

13. Liu X, Shi L, Gu J-D. Microbial electrocatalysis: Redox mediators responsible for extracellular electron transfer. Biotechnol Adv. 2018;36(7):1815-27.

14. Byrne JM, Klueglein N, Pearce C, Rosso KM, Appel E, Kappler A. Redox cycling of Fe(II) and Fe(III) in magnetite by Fe-metabolizing bacteria. Science. 2015:347(6229):1473-6.

15. Liu X, Koestler RJ, Warscheid T, Katayama Y, Gu J-D. Microbial deterioration and sustainable conservation of stone monuments and buildings. Nat Sustain. 2020;3(12):991-1004.

16. Kusumi A, Li XS, Katayama Y. Mycobacteria isolated from Angkor monument sandstones grow chemolithoautotrophically by oxidizing elemental sulfur. Front Microbiol. 2011;2:104.

17. Liu X, Wang Y, Gu J-D. Ecological distribution and potential roles of Woesearchaeota in anaerobic biogeochemical cycling unveiled by genomic analysis. Comput Struct Biotechnol J. 2021;19:794-800.

18. Gadd GM, Bahri-Esfahani J, Li Q, Rhee YJ, Wei Z, Fomina M, Liang X. Oxalate production by fungi: significance in geomycology, biodeterioration and bioremediation. Fungal Biol Rev. 2014;28(2-3):36-55.

19. Moroni B, Pitzurra L. Biodegradation of atmospheric pollutants by fungi: a crucial point in the corrosion of carbonate building stone. Int Biodeterior Biodegrad. 2008:62(4):391-6.

20. Salvadori $O$, Municchia AC. The role of fungi and lichens in the biodeterioration of stone monuments. Open Conf Proc J. 2016;7(suppl 1: M4):39-54.

21. Gorbushina AA. Life on the rocks. Environ Microbiol. 2007:9(7):1613-31.

22. Dyer T. Deterioration of stone and concrete exposed to bird excretaexamination of the role of glyoxylic acid. Int Biodeterior Biodegrad. 2017;125(Supplement C):125-41.

23. Saeki K. Adsorption of Fe ${ }^{2+}$ and $\mathrm{Mn}^{2+}$ on silica, gibbsite, and humic acids. Soil Sci. 2004;169(12):832-40.

24. Monte M. Oxalate film formation on marble specimens caused by fungus J Cult Herit. 2003;4(3):255-8.

25. de los Ríos A, Cámara B, del Cura MÁG, Rico VJ, Galván V, Ascaso C. Deteriorating effects of lichen and microbial colonization of carbonate building rocks in the Romanesque churches of Segovia (Spain). Sci Total Environ. 2009:407(3):1123-34

26. Pinna D. Biofilms and lichens on stone monuments: do they damage or protect? Front Microbiol. 2014;5:133.

27. Hallmann C, Stannek L, Fritzlar D, Hause-Reitner D, Friedl T, Hoppert M. Molecular diversity of phototrophic biofilms on building stone. FEMS Microbiol Ecol. 2013;84(2):355-72.

28. Karaca Z, Öztürk A, Çolak E. Biofouling of marbles by oxygenic photosynthetic microorganisms. Environ Sci Pollut Res. 2015;22(15):11285-9.
29. Warscheid T, Braams J. Biodeterioration of stone: a review. Int Biodeterior Biodegrad. 2000;46(4):343-68.

30. Onofri S, Zucconi L, Isola D, Selbmann L. Rock-inhabiting fungi and their role in deterioration of stone monuments in the Mediterranean area. Plant Biosyst. 2014;148(2):384-91.

31. Sterflinger K. Fungi: their role in deterioration of cultural heritage. Fungal Biol Rev. 2010;24(1):47-55

32. Othman $\mathrm{R}$, Noh NH, Hatta F, Jamaludin MA. Natural carotenoid pigments of 6 Chlorophyta freshwater green algae species. J Pharm Nutr Sci. 2018;8(1):1-5.

33. Cáceres ME, Aptroot A, Nelsen MP, Lücking R. Pyrenula sanguinea (lichenized Ascomycota: Pyrenulaceae), a new species with unique, trypethelioid ascomata and complex pigment chemistry. Bryol. 2013:116(4):350-7.

34. Wetmore CM. The lichen genus Caloplaca in North and Central America with brown or black apothecia. Mycologia. 1994;86(6):813-38.

35. Gadd GM. Geomicrobiology of the built environment. Nat Microbiol. 2017;2(4):16275.

36. Liu X, Meng H, Wang Y, Katayama Y, Gu J-D. Water is a critical factor in evaluating and assessing microbial colonization and destruction of Angkor sandstone monuments. Int Biodeterior Biodegrad. 2018;133:9-16.

37. Li X, Arai H, Shimoda I, Kuraishi H, Katayama Y. Enumeration of sulfuroxidizing microorganisms on deteriorating stone of the Angkor monuments, Cambodia. Microbes Environ. 2008;23(4):293-8.

38. Xu H-B, Tsukuda M, Takahara Y, Sato T, Gu J-D, Katayama Y. Lithoautotrophical oxidation of elemental sulfur by fungi including Fusarium solani isolated from sandstone Angkor temples. Int Biodeterior Biodegrad. 2018;126:95-102

39. Jayakumar S, Saravanane R. Biodeterioration of coastal concrete structures by macro algae-Chaetomorpha antennina. Mater Res. 2009; 12(4):465-72.

40. Chen J, Blume H-P, Beyer L. Weathering of rocks induced by lichen colonization - a review. CATENA. 2000;39(2):121-46.

41. Seaward MR. Lichens as agents of biodeterioration. In: Recent advances in lichenology. Springer; 2015. p. 189-211.

42. Yarilova YA. The role of lithophilous lichens in the weathering of massive crystalline rocks. Pochvovedeniye. 1947;3:533-48.

43. Bastian F, Jurado V, Nováková A, Alabouvette C, Saiz-Jimenez C. The microbiology of Lascaux Cave. Microbiology. 2010;156(3):644-52.

44. Zhang C, Zhang B, Cui B. High hydrophobic preservation materials can cause damage to tabia relics. Prog Org Coat. 2020;145:105683.

45. Zhou J, Liu X, Yuan F, Deng B, Yu X. Biocatalysis of heterogenouslyexpressed chitosanase for the preparation of desirable chitosan oligosaccharides applied against phytopathogenic fungi. ACS Sustain Chem Eng. 2020;8(12):4781-91.

46. Liao C, Liu X, Liu R, Shan L. Characterization and effects of two algicidal isolates on antioxidase activities of Chlorella pyrenoidosa. Environ Prog Sustain Energ. 2015;34(6):1647-51.

47. Liao C, Liu X, Liu R, Shan L. Two novel algicidal isolates kill Chlorella pyrenoidosa by inhibiting their host antioxidase activities. Appl Biochem Biotechnol. 2015;177(2):567-76.

\section{Publisher's Note}

Springer Nature remains neutral with regard to jurisdictional claims in published maps and institutional affiliations. 